Corresponding Author: Abela Mayunita; email:

mayunitaabela@yahoo.co.id

Published: 7 February 2022

Publishing services provided by

Knowledge E

(c) Abela Mayunita and Marisa

Marisa. This article is distributed

under the terms of the

Commons Attribution License,

which permits unrestricted use and redistribution provided that the original author and source are credited.

Selection and Peer-review under the responsibility of the IVCN Conference Committee.
G OPEN ACCESS

\section{The Relationship Between Education Level and Sexually Transmitted Infections in Bekasi City Hospitals}

\section{Abela Mayunita* and Marisa Marisa}

Department of Nursing, Sekolah Tinggi Ilmu Kesehatan Abdi Nusantara, Indonesia

\section{ORCID}

Abela Mayunita: https://orcid.org/0000-0003-0926-2560

Abstract. According to the World Health Organization, in 2015 there were 36.9 million people with IMS. According to West Java profile data, there were 23,301 cases of IMS in 2016, and during the period 2004-2006, there were 3,627 cases. This high level of IMS is because there are still many people with low levels of education, so their knowledge about infections is low. The purpose of the study was to determine the relationship between education level and the incidence of sexually transmitted infections in Bekasi City Hospital in 2018. This research used an analytical cross-sectional approach. The sample was the data for all patients treated in the Azalea Room for Internal Medicine at Bekasi City Hospital in 2018. Of the 221 patients who experienced sexually transmitted infections, 110 had a low education level (78.0\%), 67 had a moderate education level, and 44 had a high education level. The study results showed a relationship between the level of education and the incidence of sexually transmitted infections in the Azalea Room for Internal Medicine at the Bekasi City Hospital.

Keywords: education, sexually transmitted infections

\section{Introduction}

Sexually Transmitted Disease (STD) is one of the Reproductive Tract Infections (ISR) transmitted through sexual intercourse. Reproductive tract infection is caused by entering and breeding germs that cause infection into the reproductive tract. Germs that cause these infections can be fungi, viruses, and parasites. One of the sexually transmitted diseases is Human Immunodeficiency Virus (HIV)/Acquired Immune Deficiency Syndrome (AIDS) [1].

Based on the [2] data, 36.9 million people worldwide are affected by sexually transmitted infections. Adolescents are one of the high-risk groups for contracting IMS and HIV. The prevalence of IMS in adolescents is still high. This is due to the high rate of juvenile delinquency such as free sex, then supported by a low level of knowledge about the spread of IMS and lack of concern for the cleanliness of the reproductive organs, infected with HIV in 2014 which included 34.3 million adults, 17.4 million women and 2.6 million infected children aged $>15$ years. The number of new HIV infections 
in 2014 was 2 million, consisting of 1.8 million adults and 220,000 children aged $<15$ years. The number of deaths due to AIDS is 1.2 million, consisting of 1 million adults and 150,000 children aged $<15$ years.

From the data obtained from the [3] report, the IMS phenomena in Indonesia were the most cases of HIV/AIDs, Urethra Duh Body, and Syphilis. From October to December 2017, the number of people who interacted with HIV was 14,640 people. The highest percentage of HIV infection was reported in the 25-49 year age group (69.2\%), followed by the $20-24$ year age group (16.7\%) and the $>50$ year age group (76\%), HIV ratio between men and women are 2-1. The highest percentage of risk factors for HIV transmission in October-December 2017 was risky sex between heterosexuals (22\%), homosexuals (21\%), and the use of unsterile injecting equipment for IDUs (2\%). From October to December 2017, the number of people with AIDS was reported to be 4,725 people, the highest AIDS percentage was in the 30-39 year age group (35.2\%), followed by the $20-29$ year age group (29.5\%) and the 40 age group. -49 years $(17.7 \%)$, the ratio of AIDS between men and women is 2-1. The highest percentage of risk factors is risky sex in heterosexual (71\%) homosexuals (male sex) (20\%). From October to December 2017 , the number of cases of urethral discharge (DTU) was reported as many as 2,520 cases. Cases of genital ulcers/genital ulcers were reported as many as 489 cases, the ratio of genital ulcers between men and women was 2:1, the number of cases IMS with diagnosis based on syndromic approach and laboratory examination according to the highest risk group are female sex workers $(8,918)$; High-risk pairs $(6,579)$; Sex worker customers (1,275); shemale (759); injecting drug users (124); and male sex workers $(46)$. [3].

Based on the monitoring of the [4], the prevalence of syphilis and gonorrhea was very high. According to the statistic center departement of West Java Province, the incidence of IMS in Bogor and Depok was 61 cases in 2015 and increased in 2016 to as many as 155 cases. In the city of Bandung there were $37.4 \%$ gonorrhea cases, $34.5 \%$ chlamydia and $25.2 \%$ syphilis. In Surabaya, chlamydia cases were $33.7 \%$, syphilis $28.8 \%$, and gonorrhea $18.8 \%$. Meanwhile, in Jakarta, an urban area, the prevalence of gonorrhea cases is $29.8 \%$, syphilis is $25.2 \%$, and chlamydia is $22.7 \%$.

According to West Java health profile data, Sexually Transmitted Infections or HIV until 2016 were 23,301 cases. During the period 2004-2006, there were 3,627 of these data. More persistent efforts were needed to suppress the prevalence of IMS and HIV in West Java. Emphasis on the prevalence of IMS and HIV can be suppressed by promoting health against HIV and IMS diseases [5]. 
Sexually transmitted infections are one of the first causes of unpleasant diseases in young and old age. These problems can have a comprehensive impact regarding various aspects of life, especially in the problem of female reproductive fertility. While the impact that occurs in women who experience sexually transmitted infections can cause acute symptoms, chronic infections, and serious consequences such as infertility, ectopic pregnancy, cervical cancer, and sudden death in infants and adults. One of these impacts can be prevented by preventing sexually transmitted infections by increasing knowledge and behavior in preventing IMS based on research conducted by (Fatimah A, 2015).

Increased knowledge about IMS also impacts prevention efforts, where further prevention efforts will improve public health indicators. A person's awareness of one's health is knowledge about illness and disease, including understanding the disease, causes of disease, symptoms, and signs of disease, how to treat it, transmit it, and how to prevent disease. [6].

Based on the monitoring of the [4], the prevalence of syphilis and gonorrhea was very high. According to the [7], the incidence of IMS in Bogor and Depok was 61 cases in 2015 and increased in 2016 to as many as 155 cases. In the city of Bandung there were 37.4\% gonorrhea cases, $34.5 \%$ chlamydia and $25.2 \%$ syphilis. In Surabaya, chlamydia cases were $33.7 \%$, syphilis $28.8 \%$, and gonorrhea $18.8 \%$. Meanwhile, in Jakarta, an urban area, the prevalence of gonorrhea cases is $29.8 \%$, syphilis is $25.2 \%$, and chlamydia is $22.7 \%$.

According to West Java health profile data, Sexually Transmitted Infections or HIV until 2016 were 23,301 cases. During the period 2004-2006, there were 3,627 of these data. More persistent efforts were needed to suppress the prevalence of IMS and HIV in West Java. Emphasis on the prevalence of IMS and HIV can be suppressed by promoting health against HIV and IMS diseases [5].

Sexually transmitted infections are one of the first causes of unpleasant diseases in young and old age. These problems can have a comprehensive impact regarding various aspects of life, especially in the problem of female reproductive fertility. While the impact that occurs in women who experience sexually transmitted infections can cause acute symptoms, chronic infections, and serious consequences such as infertility, ectopic pregnancy, cervical cancer, and sudden death in infants and adults. One of these impacts can be prevented by preventing sexually transmitted infections by increasing knowledge and behavior in preventing IMS based on research conducted by (Fatimah A, 2015).

Increased knowledge about IMS also impacts prevention efforts, where further prevention efforts will improve public health indicators. A person's awareness of one's 
health is knowledge about illness and disease, including understanding the disease, causes of disease, symptoms, and signs of disease, how to treat it, transmit it, and how to prevent disease. [6].

As for the data that can be recorded in the medical records of the Bekasi City Hospital, patients who experience infectious infections, syphilis, gonorrhea, HIV/AIDS, Chlamydia, due to sex workers, LGBT, and injecting drug use, as many as 293 cases with details as follows: hospitalization in 2015 as many as 86 cases of infectious infection (17.4\%) in 2016 as many as 95 cases of infectious infection (33.6\%) in 2017 as many as 167 cases of infectious infection (45.7\%,) (Medical Records of Bekasi City Hospital, 2018). Based on the data above, the researcher is interested in conducting a study titled "The Relationship of Knowledge Levels About Reproductive Health with the Incidence of Sexually Transmitted Infections in Bekasi City Hospital in 2018".

\section{Methods}

\subsection{Design}

This study, using an analytical survey method with a cross-sectional approach.

\subsection{Sample}

In this study, the samples taken were all patients treated in the Azalea Room for Internal Medicine at the Bekasi City Hospital in 2018, with as many as 252 respondents.

\subsection{Procedure}

The location of this research was carried out at the Bekasi City Hospital in May-June 2019. This study used an analytical survey method with a cross-sectional approach, namely a study to study the dynamics of the correlation between risk factors and effects, by approach, observation, or data collection. one at a time (point in time approach).

\subsection{Questionnaire for Data Collection}

This analysis includes data tabulation and statistical calculations. 
TABLE 1: Frequency Distribution of Sexually Transmitted Infections in dr. Casbullah Abdulmadjid Hospital, Bekasi City

\begin{tabular}{l|l|l|l} 
Number & Variable & Frequency & $\%$ \\
1. & Yes & 221 & 18.7 \\
2. & No & 31 & 12.3 \\
\hline & Total & 252 & 100.0
\end{tabular}

TABLE 2: Relationship Level of Knowledge About Reproductive Health With Sexually Transmitted Infections in dr. Casbullah Abdulmajid Hospital

\begin{tabular}{|c|c|c|c|c|c|c|c|}
\hline \multirow[t]{3}{*}{ Knowledge } & \multicolumn{4}{|c|}{ Incident IMS } & \multicolumn{2}{|c|}{ Total } & \multirow[t]{2}{*}{ P. Value } \\
\hline & \multicolumn{2}{|c|}{ Yes } & \multicolumn{2}{|c|}{ No } & & & \\
\hline & $\mathrm{F}$ & $\%$ & $F$ & $\%$ & $\mathrm{~F}$ & $\%$ & \\
\hline High & 44 & 100 & 0 & 0.0 & 44 & 100.0 & \\
\hline Enough & 67 & 100 & 0 & 0.0 & 67 & 100.0 & 0.000 \\
\hline Low & 110 & 78.0 & 31 & 12.3 & 141 & 100.0 & \\
\hline Total & 221 & 87.7 & 31 & 12.2 & 252 & 100.0 & \\
\hline
\end{tabular}

\subsection{Data Analysis}

This study will use data analysis and statistical tests, including computer programs for statistical tests.

\section{Results}

Based on table 1. it can be concluded that from 252 respondents who experienced sexually transmitted infections, as many as 221 respondents (87.7\%) and the minor proportion of respondents who were not exposed to sexually transmitted infections were 31 respondents (12.3\%)

Table 2 shows that of the 44 respondents with high knowledge, the most respondents affected by sexually transmitted infections were 44 respondents (100\%), from 67 respondents with sufficient knowledge, the most respondents affected by sexually transmitted infections were 67 respondents (100\%). In comparison, from 141 respondents with shared knowledge, the most respondents who experienced Sexually Transmitted Infections were 110 respondents (87.7\%). The results of the chi-square test show that the $\mathrm{p}$-value $=.000$ ( $\mathrm{p}$-value $<0.050)$, meaning that the decision $\mathrm{Ho}$ is rejected. Ha is accepted. The conclusion is that there is a significant relationship between the level of knowledge and the incidence of sexually transmitted infections. 


\section{Discussion}

\subsection{Distribution of the frequency of occurrence of sexually trans- mitted infections}

From the results of research that has been done in RSUD, dr. Chasbullah Abdulmajid Bekasi City found that from 252 respondents, the most respondents who experienced sexually transmitted infections were 221 (87.7\%), and the least was respondents who did not experience sexually transmitted infections namely 31 (12.\%).

Knowledge is the result of human sensing or someone knowing about objects through the senses (eyes, nose, ears, and so on) [6]. In the Big Indonesian Dictionary, knowledge is known to be related to the learning process. This learning process is influenced by various internal factors, such as motivation and external factors in the form of available information facilities and socio-cultural conditions [6].

Sexually Transmitted Infections (IMS) are infections caused by bacteria, viruses, parasites, or fungi transmitted mainly through sexual contact from an infected person to their sexual partners, which causes significant clinical symptoms in the urinary tract reproductive organs.

According to [6] states that there are two determinants related to knowledge, namely: internal factors, namely the characteristics of the person concerned, which are given or innate, for example, gender, age, and emotional level and external factors, namely the environment, both the physical environment, social, cultural, economic and political, such as sources of information, discussion partners, subjects, and status of residence. It is said to have high knowledge if the score is $70-100 \%$, sufficient knowledge is $40-69 \%$, it is said to be common knowledge if the score is $<30 \%$.

Based on the results of research by Kadek Anggi Wisandewi et al., 2015, there was a relationship between the level of knowledge about health and the incidence of sexually transmitted infections. Based on the results of statistical tests obtained results with $p=$ 0.045 (p-value <0.05).

This can be prevented by maintaining some personal hygiene, especially the cleanliness of the genital area. Use clean underwear made of cotton (to maintain air circulation). Clean the genital area properly, for women do not wash the bottom towards the top or enter the herb or powder to dry the vagina. If the vagina is very dry, it will facilitate irritation and infection. Avoid unsafe relationships (Free sex). 


\subsection{Knowledge level frequency distribution}

From the results of research that researchers at RSUD, dr have done. Chasbullah Abdulmajid Bekasi City, data obtained that from 221 respondents the most respondents were respondents with a low level of knowledge $110>40 \%$, and a sufficient level of knowledge $40-49 \% 67$ (26.6\%) and respondents who had few respondents with a high level of knowledge $70-100 \% 44$ (17.5\%).

According to Skinner, as quoted by [6], if a person can answer questions about a particular field orally or in writing, he is said to know that field. The set of verbal answers that the person gives is called knowledge. Furthermore, suggesting that the knowledge included in the cognitive domain has six levels, namely:

1. Know (know) is the lowest level of knowledge. Knowing means being able to remember or recall a material that has been previously studied. The measure that someone knows is that he can mention, describe, define, and state.

2. Understanding (Comprehension), meaning the ability to explain and interpret correctly about known objects. Someone who already understands something must be able to explain, give examples and conclude.

3. Application is the ability to use the material studied in real situations and conditions and can use laws, formulas, and methods in real situations.

4. Analysis (Analysis), which means the ability to decompose objects into parts in a new whole form or the ability to new formulations from existing formulations,

5. Evaluation (Evaluation) is related to the ability to conduct research or assess material or object. These assessments are based on a specified criterion or use existing criteria.

The results of research by [8] found a relationship between the level of knowledge about health and the incidence of sexually transmitted infections. Based on the results of statistical tests, the results obtained with $p=0.045$ ( $p$-value $<0.05$ )

Therefore, health workers need to provide information about sexually transmitted infections to avoid dangerous diseases, such as HIV, etc.

\subsection{The Relationship of Knowledge Level About Reproductive Health With Sexually Transmitted Infections}

Based on the results of research that researchers at RSUD, dr have done. Chasbullah Abdulmajid Bekasi City found that out of 221 respondents who suffered from sexually transmitted infections, respondents who were highly exposed to sexually transmitted 
infections were respondents whose knowledge level was low $<0.05)$, meaning Ho was rejected. Ha was accepted. Incidence of Sexually Transmitted Infections. The odds ratio $(O R)$ value $=8.392$ means that a low level of knowledge $<40 \%$ at risk has an 8,392 times greater chance of experiencing sexually transmitted infections. Compared to a high level of knowledge, $70-100 \%$.

The results of research by [9] found a relationship between the level of knowledge about health and the incidence of sexually transmitted infections. Based on the results of statistical tests, the results were obtained with $p=0.015$ ( $p$-value $<0.05$ ) from 120 respondents.

According to Skinner, 2016 a person's knowledge, if someone can answer questions about a particular field orally or in writing, is said to know that field. A set of verbal answers given by the person is called knowledge (Knowledge). According to [6] states that there are two determinants related to knowledge, namely: internal factors, namely the characteristics of the person concerned, which are given or innate, for example, gender, age, and the emotional level and external factors, namely the environment, both physical, social, cultural, economic and political environments, such as sources of information, discussion partners, subjects, and status of residence. It is said to have high knowledge if the score is $70-100 \%$, sufficient knowledge is $40-69 \%$, it is said to be common knowledge if the score is $<30 \%$. The questions that can be used to measure knowledge in general.

According to the researchers, most of the low Knowledge Levels experienced Infectious Diseases from the data obtained. This is due to the low level of education and environmental, economic, and lack of sources of information, which are the main factors for the occurrence of sexually transmitted infections. Complementing the statement, Based on data from [4], the prevalence of syphilis and gonorrhea is very high. According to the [7], the incidence of IMS in Bogor and Depok was 61 cases in 2015 and increased in 2016 to as many as 155 cases.

\section{References}

[1] Ardhiyanti Y. AIDS textbook in midwifery and nursing care. Yogyakarta: Deepublish Publisher; 2015.

[2] World Health Organization. Sexually transmitted infections. Geneva: WHO; 2017. Available from: www.who.int/mediacentre/factsheets/fs110/en/index.html.

[3] Ministry of Health of Republic of Indonesia. National guidelines for handling sexually transmitted infections. 
[4] Central Statistic of Indonesia. Statistical activity metadata. 2017. Available from: efaidnbmnnnibpcajpcglclefindmkaj/viewer. html?pdfurl=https\%3A\%2F\%2Fsirusa. bps.go.id\%2Fwebadmin\%2Fdoc\%2Fmetadatasektoralkhusus2017.pdf\&clen= 3989059\&chunk=true

[5] Notoatmodjo, N. Health education and behavioral science. Jakarta: Rineka Cipta; 2015.

[6] Statistics Agency of West Java. Occurrence rate of sexually transmitted disease. 2017. Available from: https://jabar.bps.go.id/

[7] Kadek A. Relationship of housewives' knowledge about sexually transmitted infections. Jurnal IImu Kebidanan Poltekkes Denpasar. 2013;1(2).

[8] Suindri NN. Sexually transmitted infections and husband's support about medication adherence. Jurnal Kebidanan poltekkes Denpasar. 2013;1(2). 